\title{
Anti-infective potential of castor oil and ricinoleic acid against selected human-pathogenic bacteria
}

\author{
Sweety Biswas, Hemlatha Khairajani, Nishi Parikh, Rushika Rathod, Mittal Sangada, Pooja \\ Patel, Chinmayi Joshi, Vijay Kothari* \\ Institute of Science, Nirma University, Ahmedabad- 382481, India \\ vijay.kothari@nirmauni.ac.in; vijay23112004@yahoo.co.in
}

Castor oil (CO) and Ricinoleic acid (RA) were evaluated for their anti-infective activity against four different human-pathogenic bacteria, employing the nematode worm Caenorhabditis elegans as a model host. In vitro assays to study interaction of these two items with test bacteria with respect to bacterial growth, quorum-regulated pigment production, biofilm formation, and few other clinically relevant traits were also performed.

$\mathrm{CO}$ and RA were procured from $\mathrm{CDH}$ and Sigma-Aldrich respectively. Methodology of the in vitro and in vivo assays was adopted from our previous publications (Joshi et al., 2019; Patel et al., 2019), which also contains details of the organisms used.

Results explaining effect of CO and RA are presented through Figures 1-15, which indicate CO and RA both to be capable of attenuating virulence of pathogenic bacteria. Latter exerted activity at concentrations much lesser than that of CO. While major observations are mentioned below, full details of this study can be seen in Biswas et al. (2018).

CO $(0.5-2 \% \mathrm{v} / \mathrm{v})$ could attenuate virulence of three of the test bacteria by $25-56 \%$. It could enhance susceptibility of all the four pathogens to lysis in presence of human serum upto 20-39\%. CO could eradicate pre-formed $P$. aeruginosa biofilm by $30 \%$. Neither $P$. aeruginosa nor $S$. aureus could develop complete resistance to $\mathrm{CO}$ even after repeated exposure to this plant oil. $\mathrm{CO}$ was able to modulate quorum-regulated pigment production in all the three multidrug-resistant gram-negative bacteria used in this study. Antibiotic susceptibility of all the test pathogens was modulated upon CO-treatment.

RA $(1-20 \mu \mathrm{g} / \mathrm{mL})$ could attenuate virulence of all the three gram-negative pathogens by 4-63\%. Even repeated exposure of $P$. aeruginosa or $S$. marcescens to RA did not induce complete resistance in these pathogens. Susceptibility of three of the test pathogens to lysis in presence of human serum was enhanced upon RA-treatment by $21-77 \%$. Haemolytic potential of $P$. aeruginosa and $C$. violaceum was curbed upto $23-41 \%$ as a result of RA-pretreatment. Production of quorum-modulated pigment in all four test pathogens was modulated under influence of RA. Antibiotic susceptibility of all the four pathogens was also modulated as a result of RA-treatment.

As RA seemed to exert anti-pathogenic potential at concentrations lower than that of $\mathrm{CO}$, and since it has been known to be a constituent of CO (Patel et al., 2016); RA can be said to be largely (not necessarily solely) responsible for the anti-infective potential of $\mathrm{CO}$. 

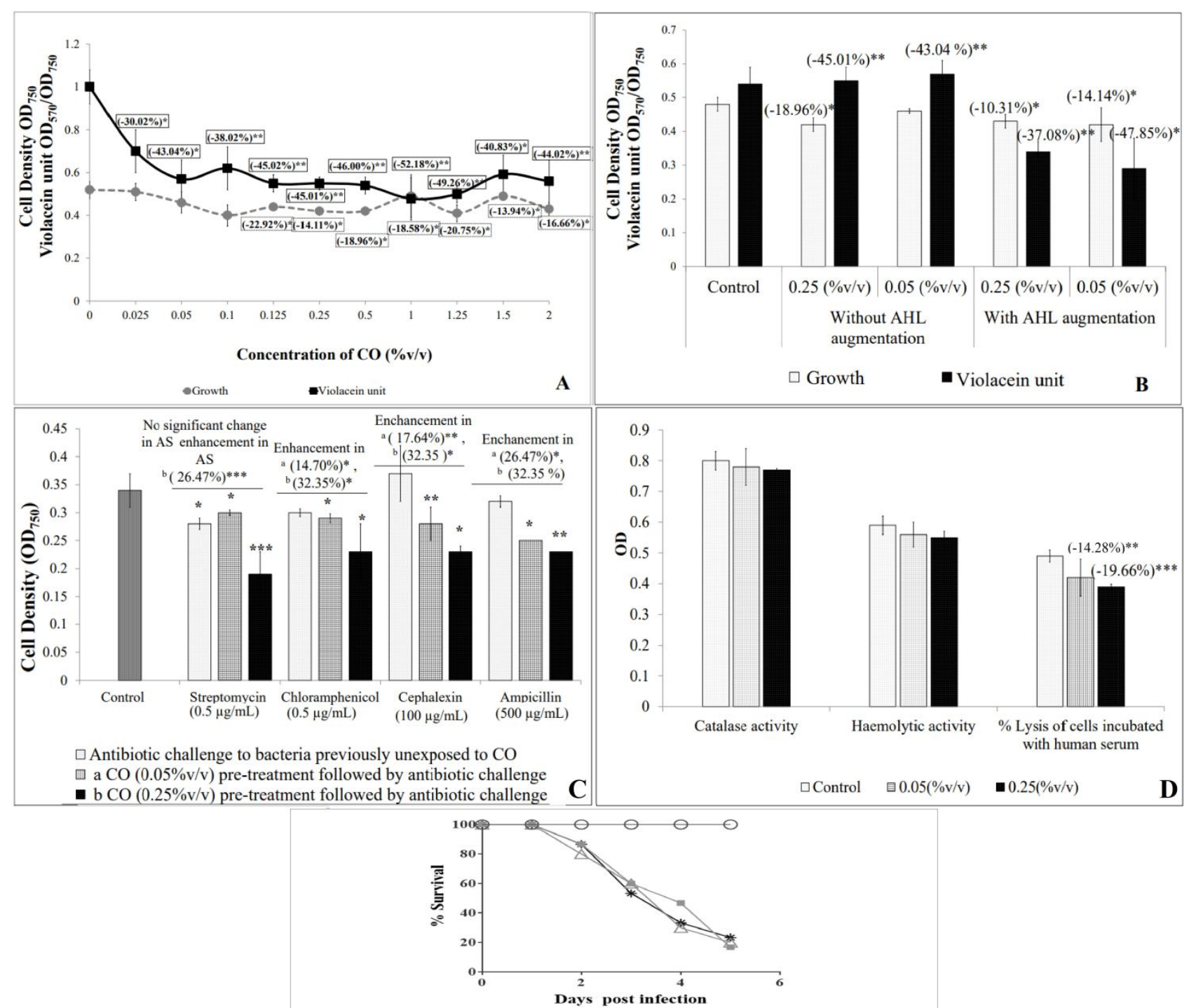

$\ominus$ Unchallenged C.elegans

- C.elegenas challeneged with C.violaceum

$\triangle$ C.elegans challeneged with CO $(0.05 \% \mathrm{v} / \mathrm{v})$-treated C.violaceum

* C.elegans challeneged with CO $(0.25 \% \mathrm{v} / \mathrm{v})$-treated C.violaceum

$\mathbf{E}$

\section{Figure 1. Effect of castor oil on Chromobacterium violaceum}

$*_{p}<0.05, * * p<0.01, * * * p<0.001$; AS: Antibiotic susceptibility; QS: Quorum sensing; CO: Castor Oil

(A) Effect of CO on growth and QS-regulated violacein production in C. violaceum: Bacterial cell density was quantified as $\mathrm{OD}_{750}$; $\mathrm{OD}$ of violacein was measured at $570 \mathrm{~nm}$, and Violacein Unit was calculated as the ratio $\mathrm{OD}_{570} / \mathrm{OD}_{750}$ (an indication of violacein production per unit of growth); (B) CO acts as a signal-response inhibitor against $C$. violaceum. (C) CO-pre-treatment enhances susceptibility of $C$. violaceum to different antibiotics. (D) $\mathrm{CO}$ had no effect on catalase activity and haemolytic activity of $C$. violaceum, but it modulates susceptibility of $C$. violaceum to lysis by human serum: Catalase activity was assessed by monitoring disappearance of $\mathrm{H}_{2} \mathrm{O}_{2}$ at $240 \mathrm{~nm}$. Hemoglobin concentration was measured as $\mathrm{OD}_{490 .} 1 \%$ triton served as the positive control $\left(\mathrm{OD}_{490}=1.6 \pm 0.004\right)$, and PBS served as the negative control $\left(\mathrm{OD}_{490}=0.02 \pm 0.004\right)$ for this assay. 'Control' in serum-dependent lysis assay was $\mathrm{CO}$ unexposed cells of $C$. violaceum incubated with human serum. (E) CO-treatment attenuates virulence of $C$. violaceum towards $C$. elegans: Catechin $(50 \mu \mathrm{g} / \mathrm{mL})$ and ampicillin $(500 \mu \mathrm{g} / \mathrm{mL})$ employed as positive controls conferred $100 \%$ protection on worm population, and CO at $0.05 \% \mathrm{v} / \mathrm{v}$ and $0.25 \% \mathrm{v} / \mathrm{v}$ conferred $4 \% * * * \pm 0.28$ and $7.33 \% * * * \pm 0.15$ survival benefit, respectively. Survival benefit refers to the difference between number of worms surviving in experimental and control wells. $\mathrm{CO}$ at tested concentrations showed no toxicity towards the worm. 


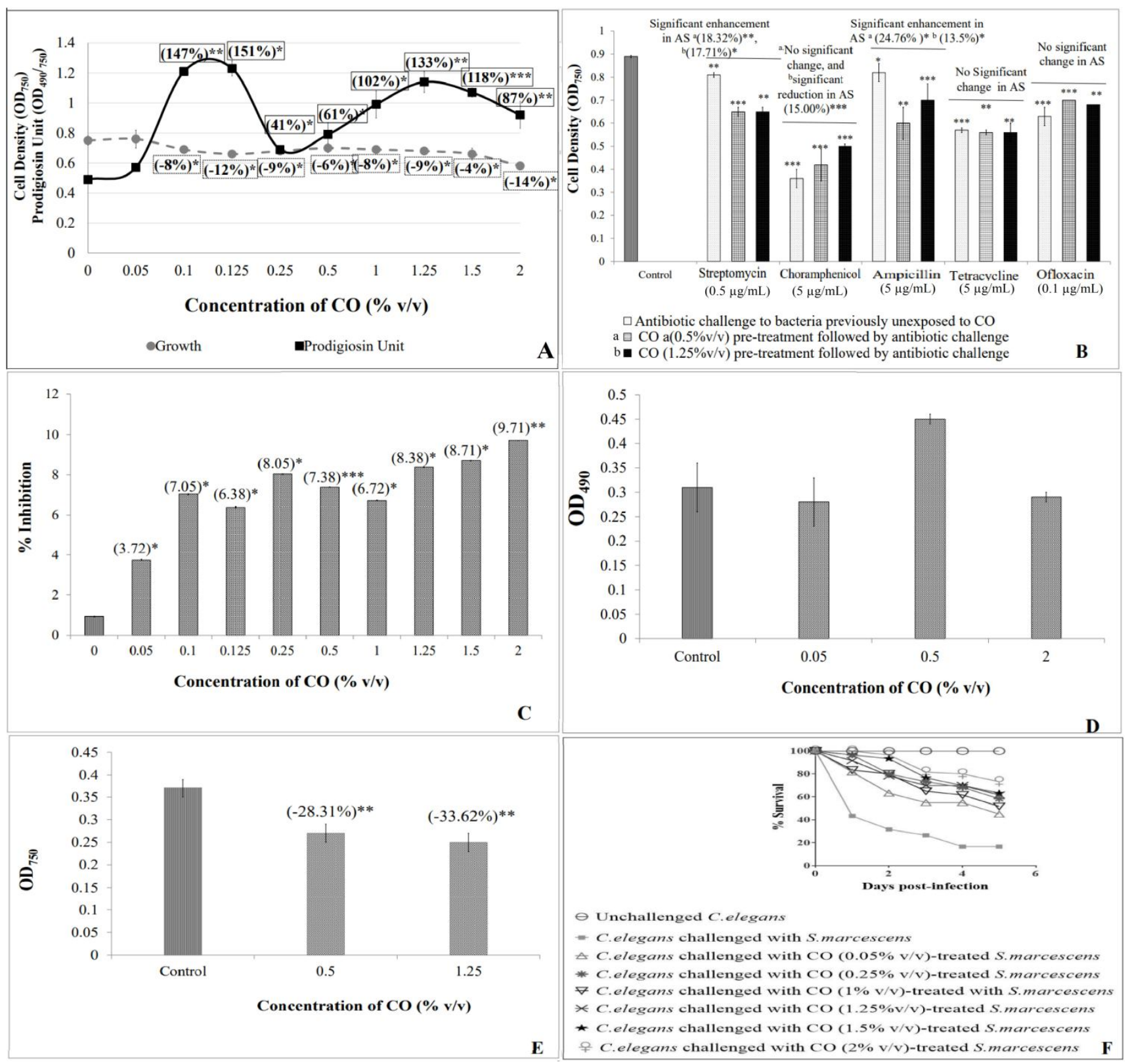

Figure 2. Effect of castor oil on Serratia marcescens

$*_{p}<0.05$, ** $p<0.01, * * * p<0.001$; AS: Antibiotic susceptibility; QS: Quorum sensing; CO: Castor Oil

(A) Effect of CO on growth and QS-regulated prodigiosin production in $\mathbf{S}$. marcescens: Bacterial cell density was quantified as $\mathrm{OD}_{750}$; $\mathrm{OD}$ of prodigiosin was measured at $490 \mathrm{~nm}$, and Prodigiosin Unit was calculated as the ratio $\mathrm{OD}_{490} / \mathrm{OD}_{750}(\mathrm{an}$ indication of prodigiosin production per unit of growth). (B) CO-pre-treatment modulates susceptibility of $S$.

marcescens to different antibiotics. (C) $\mathrm{CO}$ enhances catalase activity of $\boldsymbol{S}$ marcescens: Catalase activity was assessed by monitoring disappearance of $\mathrm{H}_{2} \mathrm{O}_{2}$ at $240 \mathrm{~nm}$. (D) CO had no effect on haemolytic activity of $\boldsymbol{S}$

marcescens: Hemoglobin concentration was measured as $\mathrm{OD}_{490} .1 \%$ triton served as the positive control $\left(\mathrm{OD}_{490}=1.6 \pm 0.004\right)$, and PBS served as the negative control $\left(\mathrm{OD}_{490}=0.02 \pm 0.004\right)$ for this assay. (E) CO modulates susceptibility of $\boldsymbol{S}$.

marcescens to lysis by human serum: 'Control' in serum-dependent lysis assay was CO-unexposed cells of S. marcescens incubated with human serum. (F) CO-treatment reduces virulence of $S$. marcescens towards $C$. elegans: Catechin $(50 \mu \mathrm{g} / \mathrm{mL})$ and ofloxacin $(0.1 \mu \mathrm{g} / \mathrm{mL})$ employed as positive controls conferred $100 \%$ and $80 \%$ protection on worm population, respectively. Pre-treatment of bacteria with CO at $0.05,0.1,0.125,0.25,0.5,1,1.25,1.5$ and $2 \% \mathrm{v} / \mathrm{v}$ conferred $28.34 \% \%^{* * *}$ $2.28,29.94 \% * * * \pm 3.33,31.64 \% * * * \pm 2.84,41.64 \% * * * \pm 3.28,38.34 \% * * \pm 4.28,34.94 \% * * * \pm 2.28,44.94 \% * * * \pm 3.34,46.64 \% * * \pm$ 4.46 and $56.64 \% * * * \pm 4.48$ survival benefit, respectively; Survival benefit refers to the difference between number of worms surviving in experimental and control wells. $\mathrm{CO}$ at tested concentrations showed no toxicity towards the worm. 


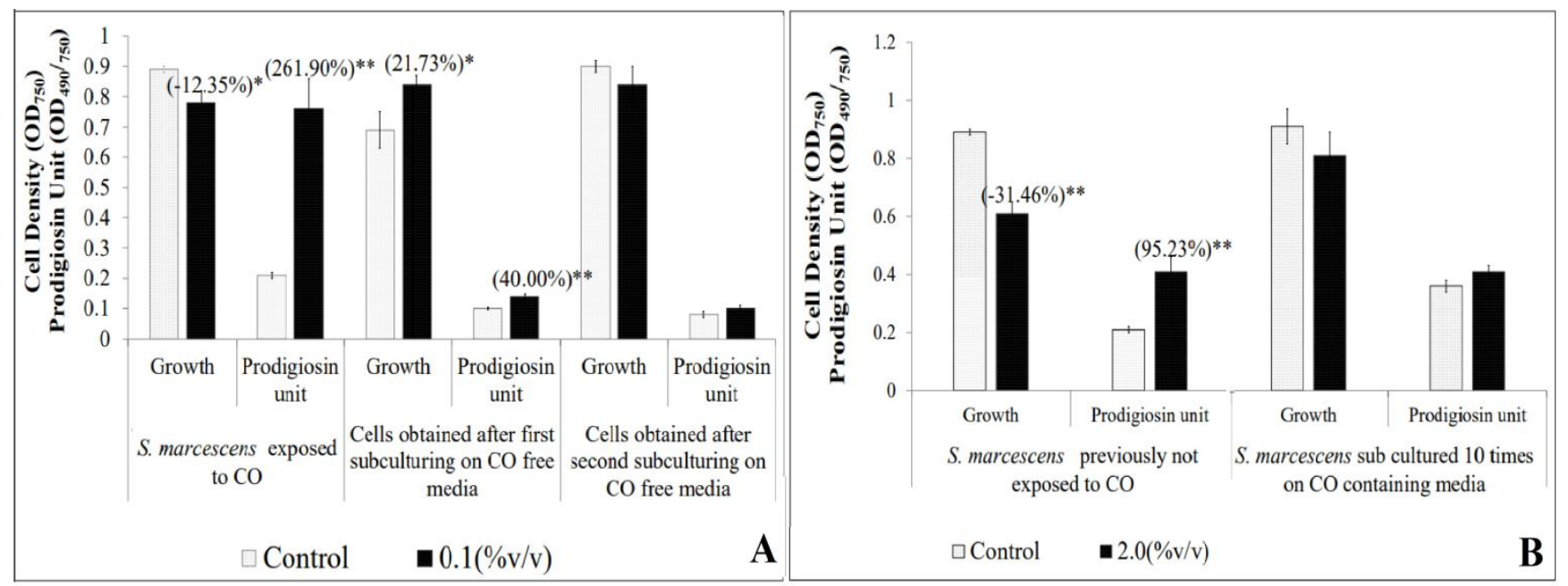

Figure 3. Effect of castor oil on various traits of $S$. marcescens, in vitro

$* p<0.05, * * p<0.01$; CO: Castor Oil

(A) Demonstration of post-extract effect of $\mathrm{CO}$ on $\mathrm{S}$. marcescens in vitro. (B) Effect of $\mathrm{CO}$ on S. marcescens growth, and pigment production altered after repeated exposure to $\mathrm{CO}$.

Bacterial cell density was quantified as $\mathrm{OD}_{750}$; OD of prodigiosin was measured at $490 \mathrm{~nm}$, and Prodigiosin Unit was calculated as the ratio $\mathrm{OD}_{490} / \mathrm{OD}_{750}$ (an indication of prodigiosin production per unit of growth). 


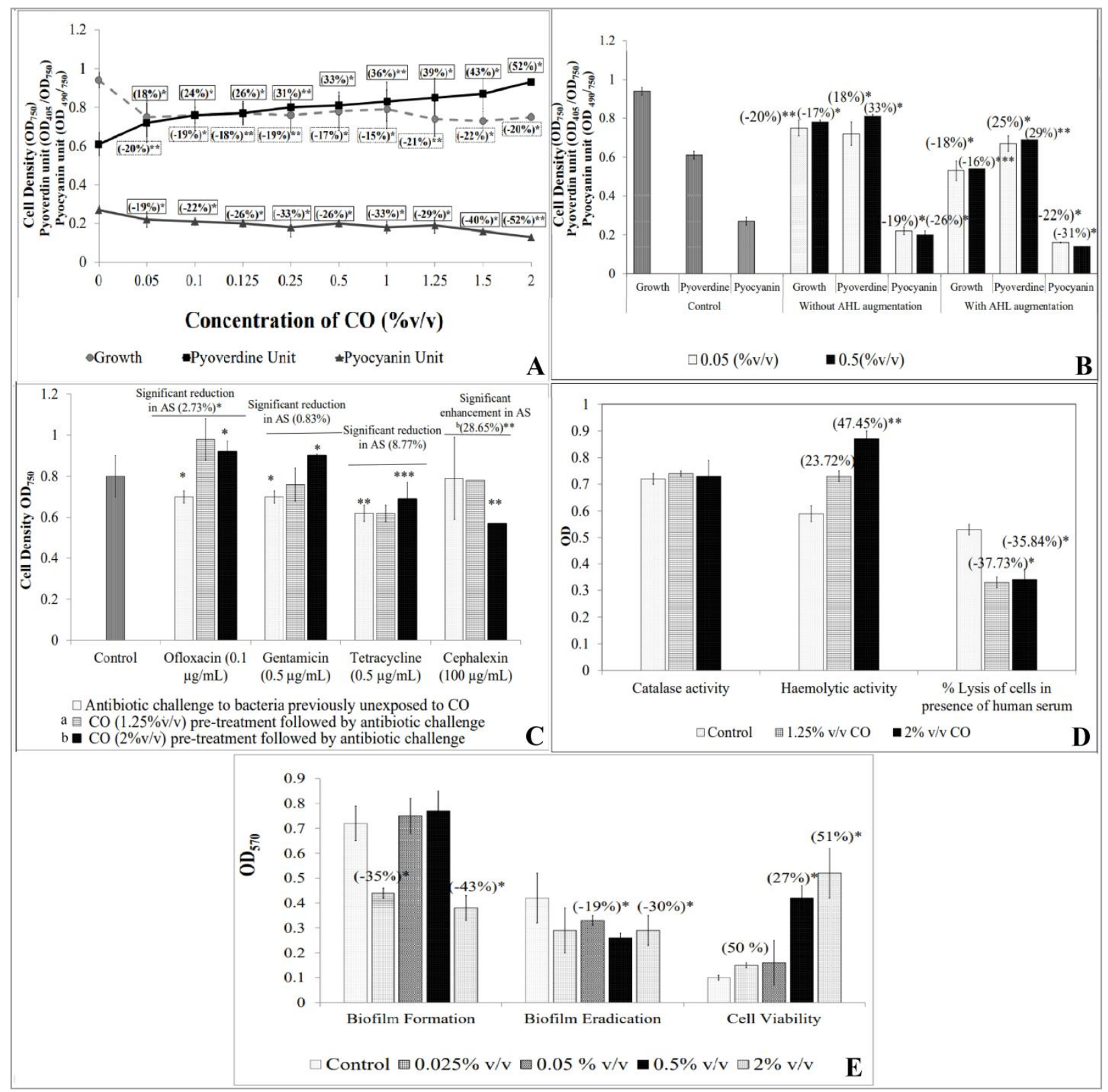

Figure 4. Effect of castor oil on Pseudomonas aeruginosa

${ }^{*} p<0.05, * * p<0.01, * * * p<0.001$; AS: Antibiotic susceptibility; QS: Quorum sensing; CO: Castor Oil; PBS: Phosphate buffer saline

(A) Effect of $\mathrm{CO}$ on growth and QS-regulated pigment production in $\boldsymbol{P}$. aeruginosa: Bacterial cell density was quantified as $\mathrm{OD}_{750}$; OD of pyoverdine was measured at $405 \mathrm{~nm}$, Pyocyanin was measured at $490 \mathrm{~nm}$. Pyoverdine Unit was calculated as the ratio $\mathrm{OD}_{405} / \mathrm{OD}_{750}(\mathrm{an}$ indication of pyoverdine production per unit of growth); Pyocyanin Unit was calculated as the ratio $\mathrm{OD}_{490} / \mathrm{OD}_{750}$ (an indication of pyocyanin production per unit of growth. (B) CO acts as a signal-response inhibitor against $P$. aeruginosa. (C) CO-treatment made $P$. aeruginosa more susceptible to cephalexin (D) CO had no effect on catalase activity, enhances haemolytic activity, and increases susceptibility of $\boldsymbol{P}$. aeruginos $\boldsymbol{a}$ to lysis by human serum: Catalase activity was assessed by monitoring disappearance of $\mathrm{H}_{2} \mathrm{O}_{2}$ at $240 \mathrm{~nm}$. Hemoglobin concentration was measured as $\mathrm{OD}_{490} .1 \%$ triton served as the positive control $\left(\mathrm{OD}_{490}=1.6 \pm 0.004\right)$, and PBS served as the negative control $\left(\mathrm{OD}_{490}=0.01 \pm 0.00\right)$ for this assay. 'Control' in serum-dependent lysis assay was CO-unexposed cells of $P$. aeruginosa incubated with human serum. (E) CO reduced $P$. aeruginosa biofilm formation, eradicated pre-formed biofilm, but it enhanced biofilm viability: Crystal violet assay was performed to measure biofilm formation, and biofilm eradication, followed by the measurement of OD at $570 \mathrm{~nm}$; Cell viability in biofilm was estimated through MTT assay, wherein OD was measured at $570 \mathrm{~nm}$. 

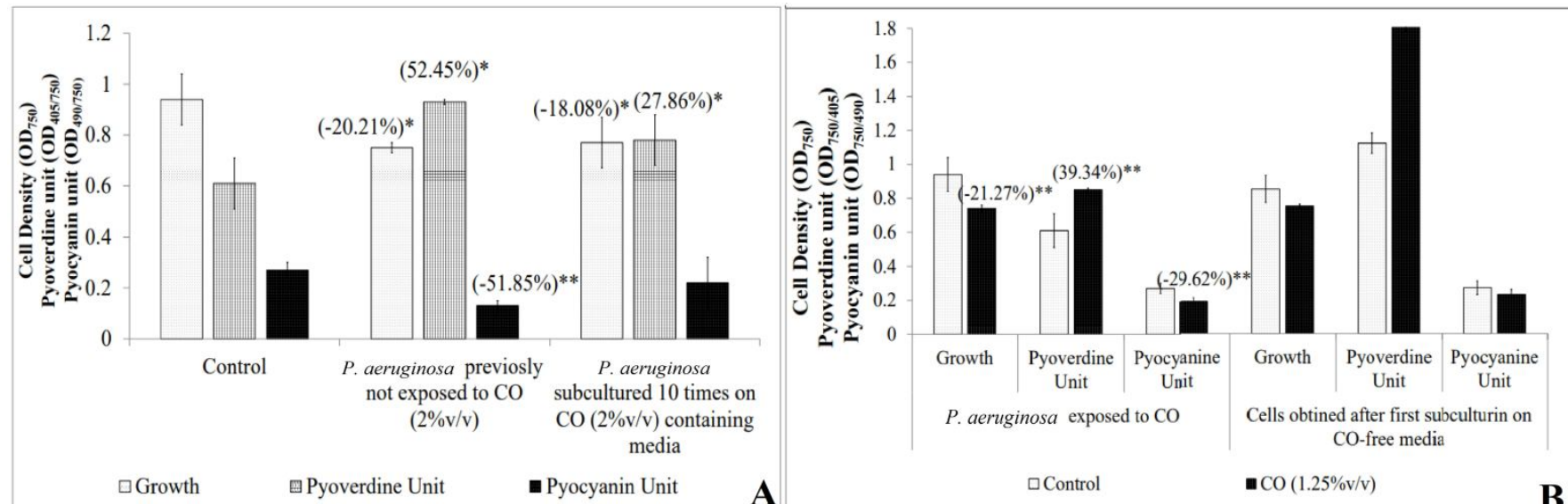

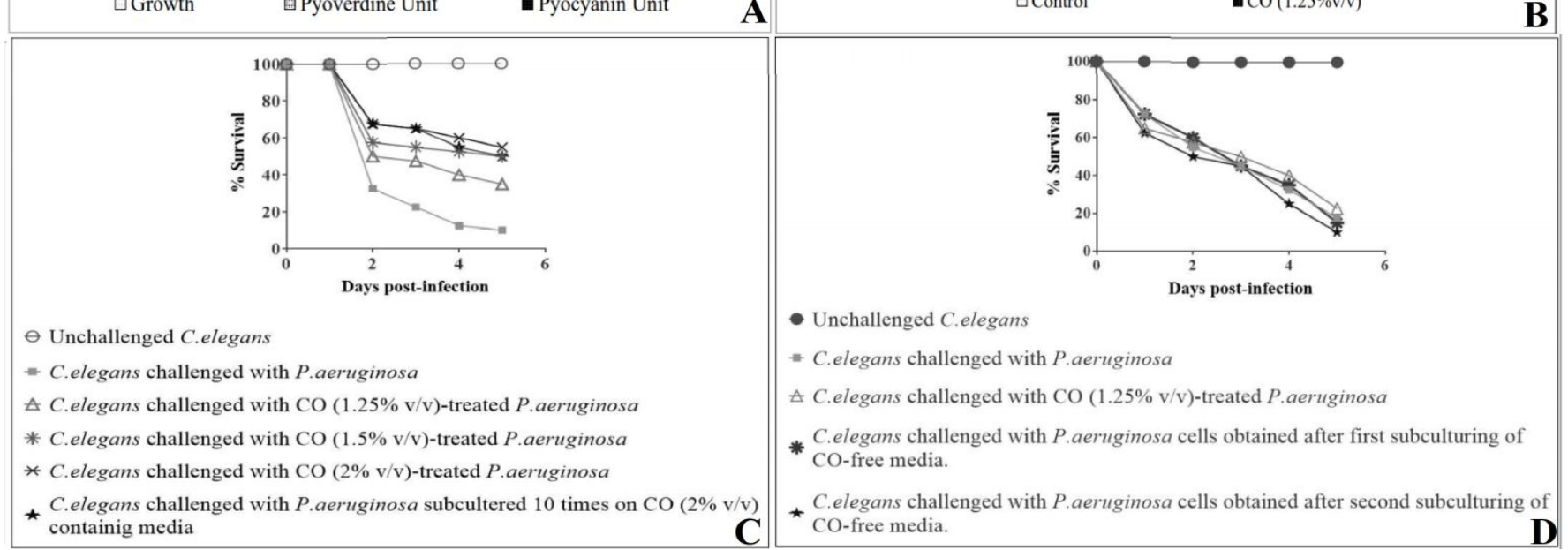

\section{Figure 5. Effect of $\mathrm{CO}$ on various traits of $P$. aeruginosa, in vitro and in vivo $* p<0.05, * * p<0.01, * * * p<0.001$; CO: Castor Oil}

(A) Effect of $\mathrm{CO}$ on $P$. aeruginosa growth and pyoverdine production remained unaltered, while pyocyanin production was altered after repeated exposure to CO. (B) No Post Extract Effect of CO on P. aeruginosa was observed in vitro: Bacterial cell density was quantified as $\mathrm{OD}_{750}$; $\mathrm{OD}$ of pyoverdine was measured at $405 \mathrm{~nm}$, Pyocyanin was measured at 490 $\mathrm{nm}$. Pyoverdine Unit was calculated as the ratio $\mathrm{OD}_{405} / \mathrm{OD}_{750}$ (an indication of pyoverdine production per unit of growth); Pyocyanin Unit was calculated as the ratio $\mathrm{OD}_{490} / \mathrm{OD}_{750}$ (an indication of pyocyanin production per unit of growth) (C) CO-treatment reduces the virulence of

$\boldsymbol{P}$. aeruginosa towards $\boldsymbol{C}$. elegans: Catechin $(50 \mu \mathrm{g} / \mathrm{mL})$ and gentamicin $(0.1 \mu \mathrm{g} / \mathrm{mL})$ employed as positive controls conferred $100 \%$ protection on worm population. $\mathrm{CO}$ at $1,1.25,1.5$ and $2 \% \mathrm{v} / \mathrm{v}$ conferred, $5 \% * * \pm 0.82,25 \% * * * \pm 2.28,40 \% * * * \pm 3.28$ and $45 \% * * * \pm 4.45$ survival benefit respectively. Survival benefit refers to the difference between number of worms surviving in experimental and control wells. CO at tested concentrations showed no toxicity towards C. elegans. (D) Post-extract effect of CO on P. aeruginosa in vivo 

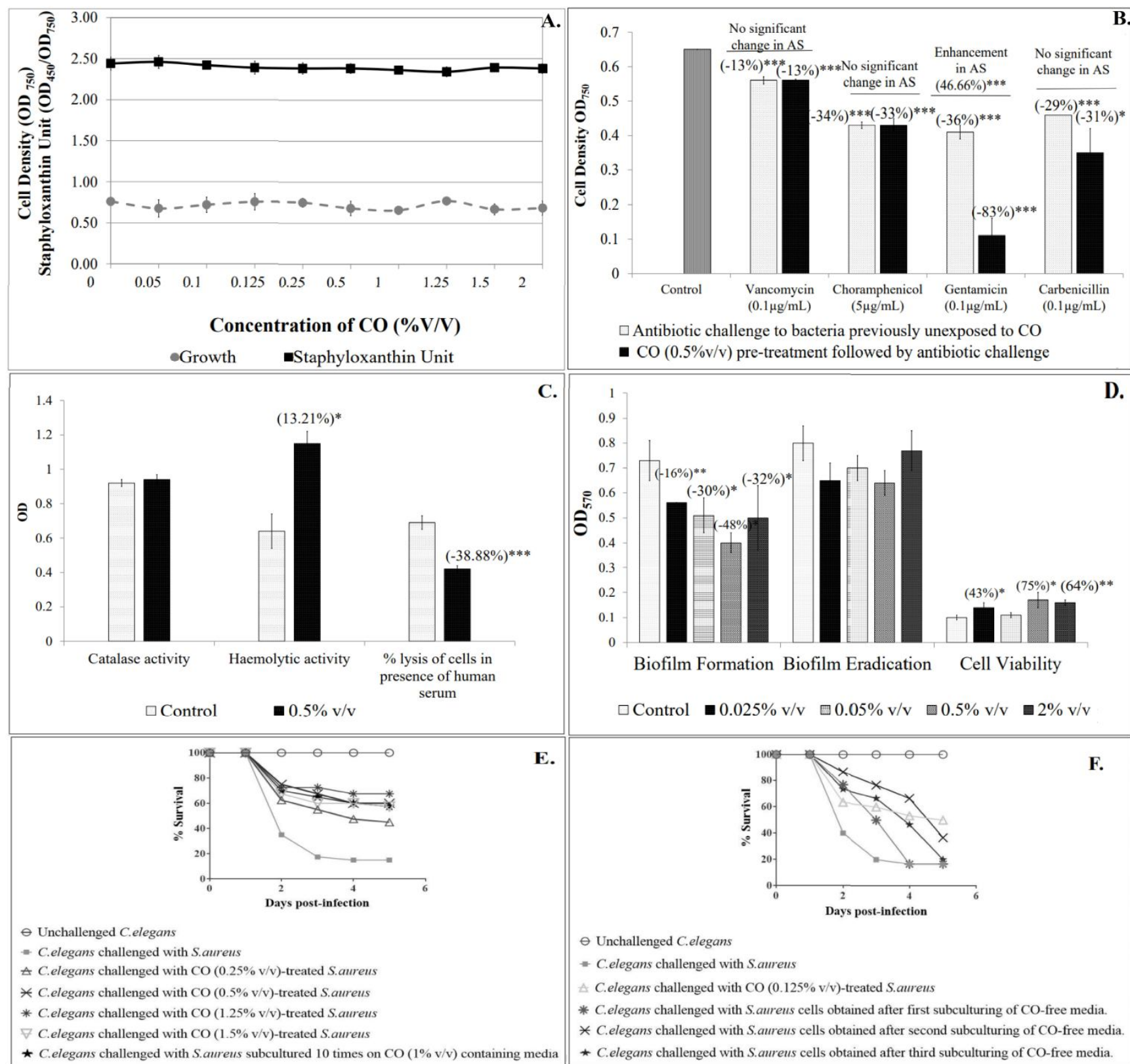

E.

$\square$ Control $\square 0.025 \% \mathrm{v} / \mathrm{v} \square 0.05 \% \mathrm{v} / \mathrm{v} \square 0.5 \% \mathrm{v} / \mathrm{v} \quad \square 2 \% \mathrm{v} / \mathrm{v}$

Figure 6. Effect of castor oil on Staphylococcus aureus

${ }^{*} p<0.05, * * p<0.01, * * * p<0.001$; AS: Antibiotic susceptibility; QS: Quorum sensing; CO: Castor oil, PBS: Phosphate buffer saline

(A) Effect of $\mathrm{CO}$ on growth and QS-regulated pigment production in S. aureus: Bacterial cell density was quantified as

$\mathrm{OD}_{750}$; $\mathrm{OD}$ of staphyloxanthin was measured at $450 \mathrm{~nm}$, and Staphyloxanthin Unit was calculated as the ratio $\mathrm{OD}_{450} / \mathrm{OD}_{750}$ (an indication of staphyloxanthin production per unit of growth). (B) CO-treatment made S. aureus more susceptible to gentamicin. (C) CO had no effect on catalase activity, enhances haemolytic activity, and modulates susceptibility of $S$. aureus to lysis by human serum: Catalase activity was assessed by monitoring disappearance of $\mathrm{H}_{2} \mathrm{O}_{2}$ at $240 \mathrm{~nm}$; Hemoglobin concentration was measured as $\mathrm{OD}_{490}$. $1 \%$ triton served as the positive control $\left(\mathrm{OD}_{490}=1.6 \pm 0.004\right)$, and PBS served as the negative control $\left(\mathrm{OD}_{490}=0.02 \pm 0.004\right)$ for this assay; 'Control' in serum-dependent lysis assay was $C O$-unexposed cells of $S$. aureus incubated with human serum. (D) CO reduced $P$. aeruginosa biofilm formation, had no

effect on eradicated pre-formed biofilm, but enhanced biofilm viability: Crystal violet assay was performed to measure biofilm formation, and biofilm eradication, followed by the measurement of OD at $570 \mathrm{~nm}$; Cell viability in biofilm was estimated through MTT assay, wherein OD was measured at $570 \mathrm{~nm}$. (E) CO-treatment reduces the virulence of $\boldsymbol{S}$. aureus towards C. elegans: Catechin (50 $\mu \mathrm{g} / \mathrm{mL})$ and gentamicin $(0.1 \mu \mathrm{g} / \mathrm{mL})$ employed as a positive controls conferred $100 \%$ protection on worm population. $0.05,0.1,0.125,0.25,0.5,1$, $1.25,1.5$ and $2 \% \mathrm{v} / \mathrm{v}$ conferred $0 \%, 10 \% * \pm 1.01,27.5 \% * * \pm 2.28,30 \% * * * \pm 3.23,45 \% * * \pm 4.42,52.5 \% * * * \pm 3.23,52.5 \% * * * \pm 2.28,37.5 \% * * \pm 4.22$ and $40 \% * * * 3.52$ survival benefit, respectively. Survival benefit refers to the difference between number of worms surviving in experimental and control wells. CO at tested concentrations showed no toxicity towards C. elegans. (F) Post-extract effect of CO on S. aureus in vivo 


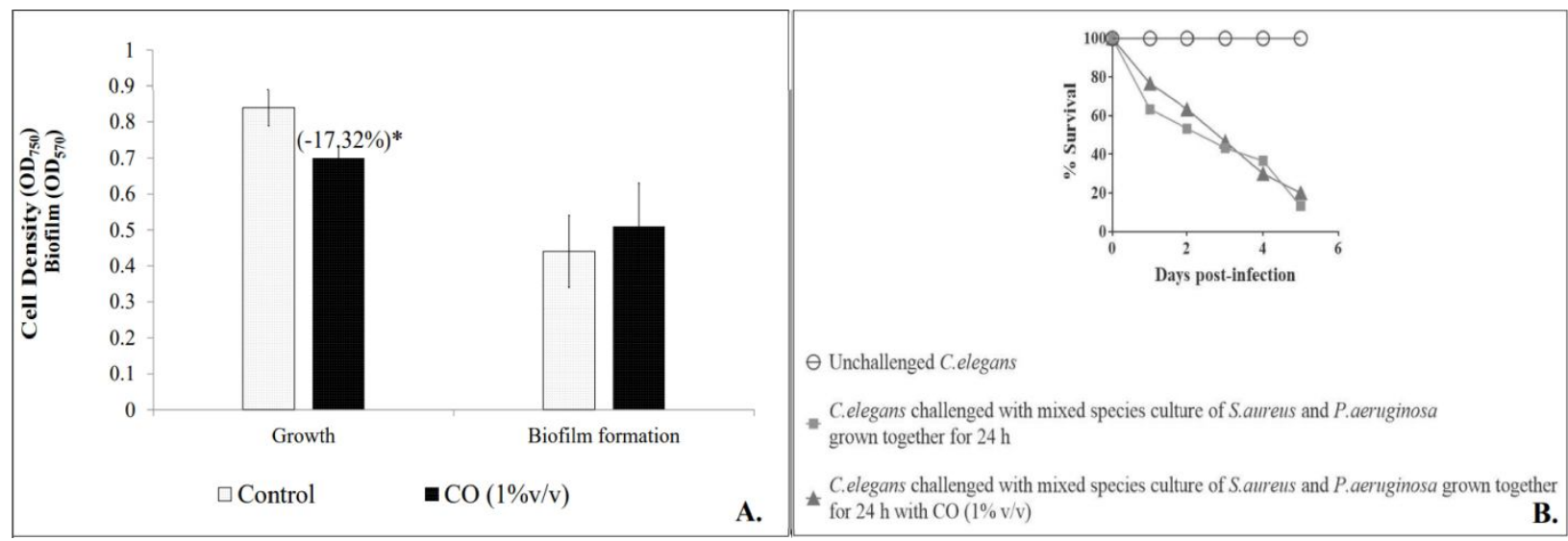

Figure 7. Effect of CO on mix-species culture of $P$. aeruginosa and $S$. aureus

(A) Biofilm formation (B) Anti-virulence effect of $\mathrm{CO}$ on mix-species culture of P. aeruginosa and $S$. aureus 


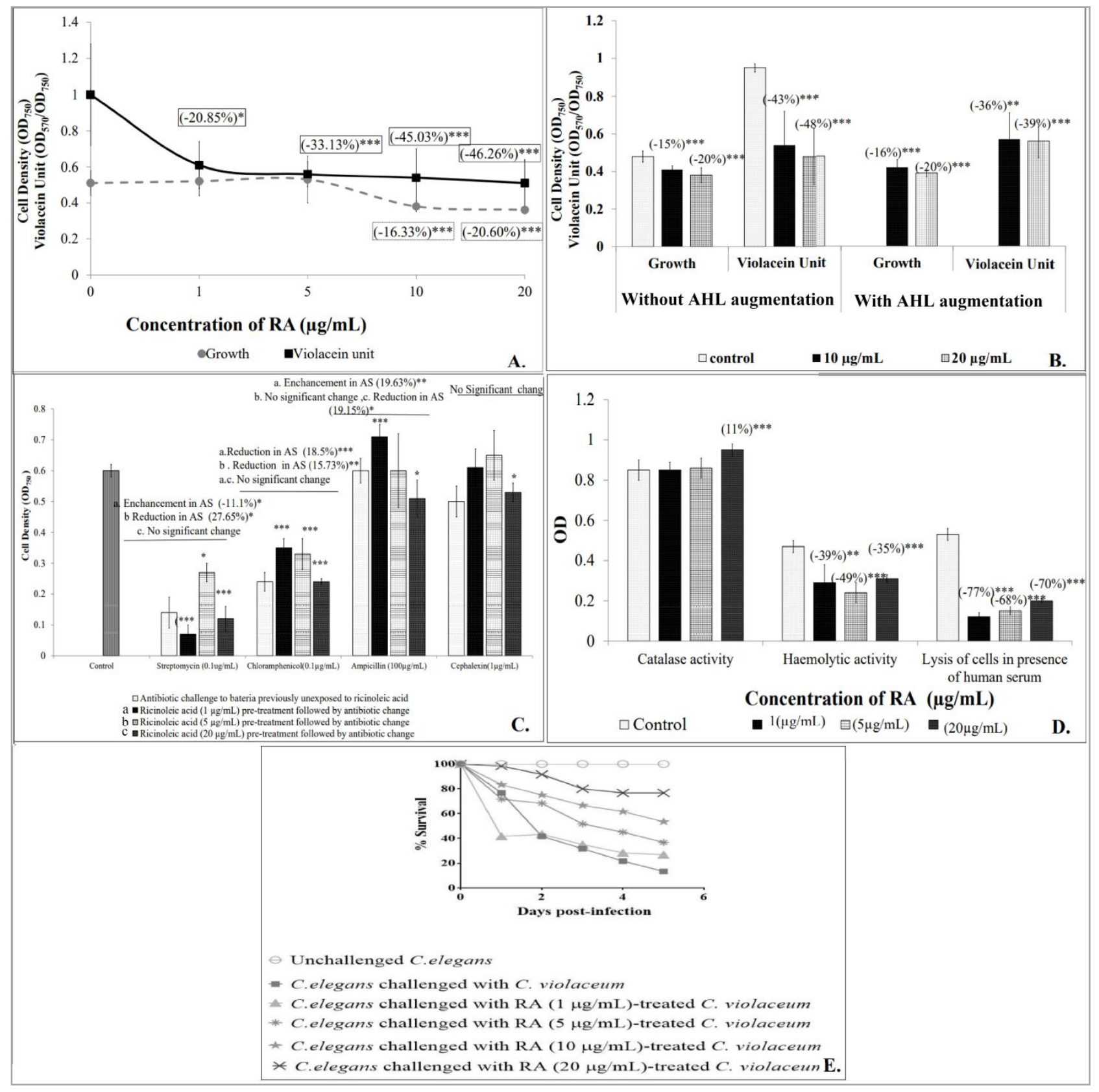

Figure 8. Effect of ricinoleic acid on Chromobacterium violaceum

${ }^{*}<0.05,{ }^{* *} p<0.01, * * * p<0.001$; AS: Antibiotic susceptibility; QS: Quorum sensing; RA: Ricinoleic acid

(A) Effect of RA on growth and QS-regulated violacein production in $\boldsymbol{C}$. violaceum: Bacterial cell density was quantified as $\mathrm{OD}_{750}$; OD of violacein was measured at $570 \mathrm{~nm}$, and Violacein Unit was calculated as the ratio $\mathrm{OD}_{570} / \mathrm{OD}_{750}$ (an indication of violacein production per unit of growth). (B) RA acts as a signal-response inhibitor against $C$. violaceum. (C) RA-pre-treatment modulates susceptibility of $C$. violaceum to different antibiotics. (D) RA enhances catalase activity and inhibits haemolytic of C. violaceum but $\mathrm{RA}$ modulates susceptibility of $C$. violaceum to lysis by human serum: Catalase activity was assessed by monitoring disappearance of $\mathrm{H}_{2} \mathrm{O}_{2}$ at $240 \mathrm{~nm}$. Hemoglobin concentration was measured as $\mathrm{OD}_{490} .1 \%$ triton served as the positive control $\left(\mathrm{OD}_{490}=1.5\right.$ $\pm 0.005)$, and PBS served as the negative control $\left(\mathrm{OD}_{490}=0.03 \pm 0.004\right)$ for this assay. 'Control' in serum-dependent lysis assay was RA-unexposed cells of $C$. violaceum incubated with human serum. (E) RA-treatment attenuates virulence of $C$. violaceum towards $C$. elegans: Catechin $(50 \mu \mathrm{g} / \mathrm{mL})$ and ampicillin $(500 \mu \mathrm{g} / \mathrm{mL})$ employed as positive controls conferred $100 \%$ protection on worm population, and RA at $1 \mu \mathrm{g} / \mathrm{mL}, 5$ $\mu \mathrm{g} / \mathrm{mL}, 10 \mu \mathrm{g} / \mathrm{mL}, 20 \mu \mathrm{g} / \mathrm{mL}$ conferred $13.33 \% * \pm 1.28$ and $23.33 \% * * * \pm 1.25,40 \% * * * \pm 2.28,63.33 \% * * * \pm 3.23$ survival benefit, respectively. Survival benefit refers to the difference between number of worms surviving in experimental and control wells. DMSO present in the 'vehicle control' at $0.5 \% \mathrm{v} / \mathrm{v}$ did not affect virulence of the bacterium towards C. elegans; DMSO $(0.5 \% \mathrm{v} / \mathrm{v})$ and RA at tested concentrations showed no toxicity towards the worm. 


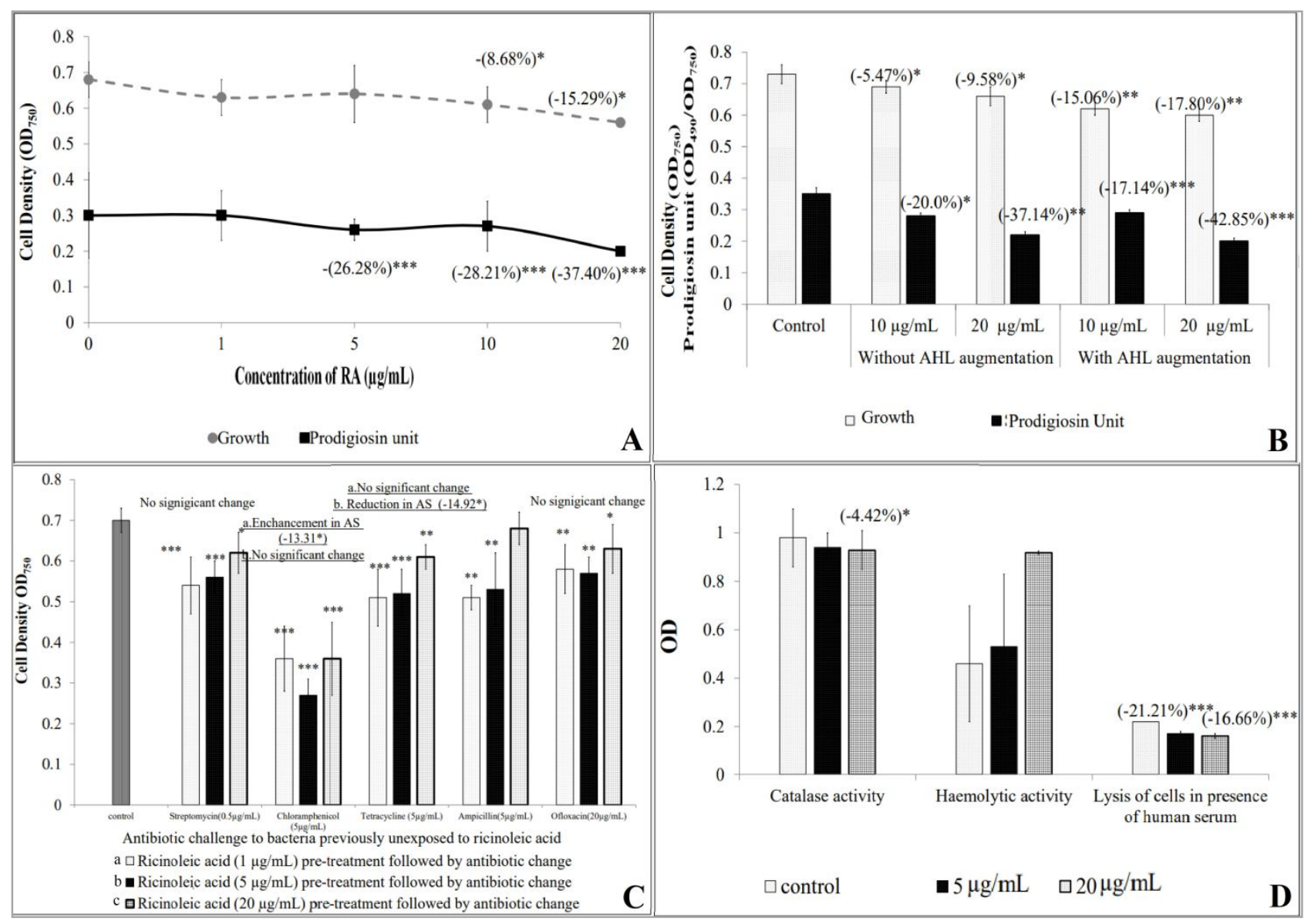

Figure 9. Effect of ricinoleic acid on Serratia marcescens

${ }^{*} p<0.05, * * p<0.01, * * * p<0.001$; AS: Antibiotic susceptibility; QS: Quorum sensing; RA: Ricinoleic acid

(A) Effect of RA on growth and QS-regulated prodigiosin production in S. marcescens: Bacterial cell density was quantified as $\mathrm{OD}_{750}$; OD of prodigiosin was measured at $490 \mathrm{~nm}$, and Prodigiosin Unit was calculated as the ratio $\mathrm{OD}_{490} / \mathrm{OD}_{750}($ an indication of prodigiosin production per unit of growth). (B) RA acts as a signal-response inhibitor against S. marcescens. (C) RA-pretreatment modulates susceptibility of $S$. marcescens to different antibiotics. (D) CO inhibits catalase activity but had no effect on haemolytic activity, and it enhances susceptibility of $\boldsymbol{S}$. marcescens to lysis by human serum: Catalase activity was assessed by monitoring disappearance of $\mathrm{H}_{2} \mathrm{O}_{2}$ at $240 \mathrm{~nm}$. Hemoglobin concentration was measured as $\mathrm{OD}_{490} .1 \%$ triton served as the positive control $\left(\mathrm{OD}_{490}=1.6 \pm 0.004\right)$, and PBS served as the negative control $\left(\mathrm{OD}_{490}=0.03 \pm 0.005\right)$ for this assay. 'Control' in serum-dependent lysis assay was RA-unexposed cells of $S$. marcescens incubated with human serum. 


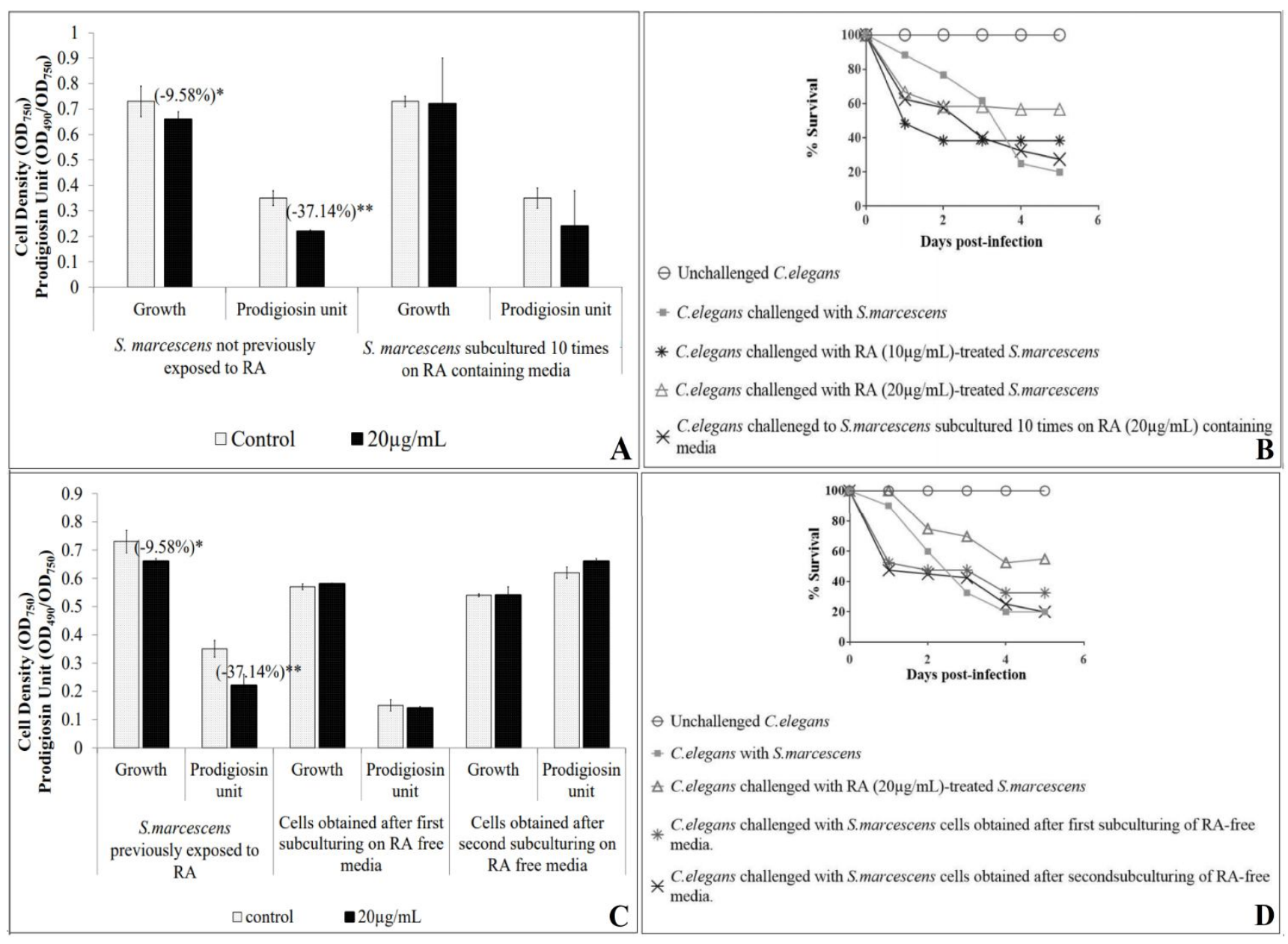

Figure 10. Effect of ricinoleic acid on various traits of $S$. marcescens, in vitro and in vivo ${ }^{*} p<0.05, * * p<0.01, * * * p<0.001$; RA: Ricinoleic acid

(A) Effect of RA on S. marcescens growth and Prodigiosin Unit altered after repeated exposure to RA: Bacterial cell density was quantified as $\mathrm{OD}_{750}$; $\mathrm{OD}$ of prodigiosin was measured at $490 \mathrm{~nm}$. Prodigiosin Unit was calculated as the ratio $\mathrm{OD}_{490} / \mathrm{OD}_{750}$ (an indication of prodigiosin production per unit of growth). (B) RA-treatment reduces the virulence of S. marcescens towards C. elegans: Catechin $(50 \mu \mathrm{g} / \mathrm{mL})$ and gentamicin $(0.1 \mu \mathrm{g} / \mathrm{mL})$ employed as positive controls conferred $100 \%$ protection on worm population. RA at $10 \mu \mathrm{g} / \mathrm{mL}, 20$ $\mu \mathrm{g} / \mathrm{mL}$ conferred 28.33 and 46.66 survival respectively. Survival benefit refers to the difference between number of worms surviving in experimental and control wells. DMSO present in the 'vehicle control' at $0.5 \% \mathrm{v} / \mathrm{v}$ did not affect virulence of the bacterium towards C. elegans; DMSO (0.5\%v/v) and RA at tested concentrations showed no toxicity towards C. elegans. (C) No Post Extract Effect of RA on S. marcescens was observed in vitro (D) Post-extract effect of RA on S. marcescens in vivo 


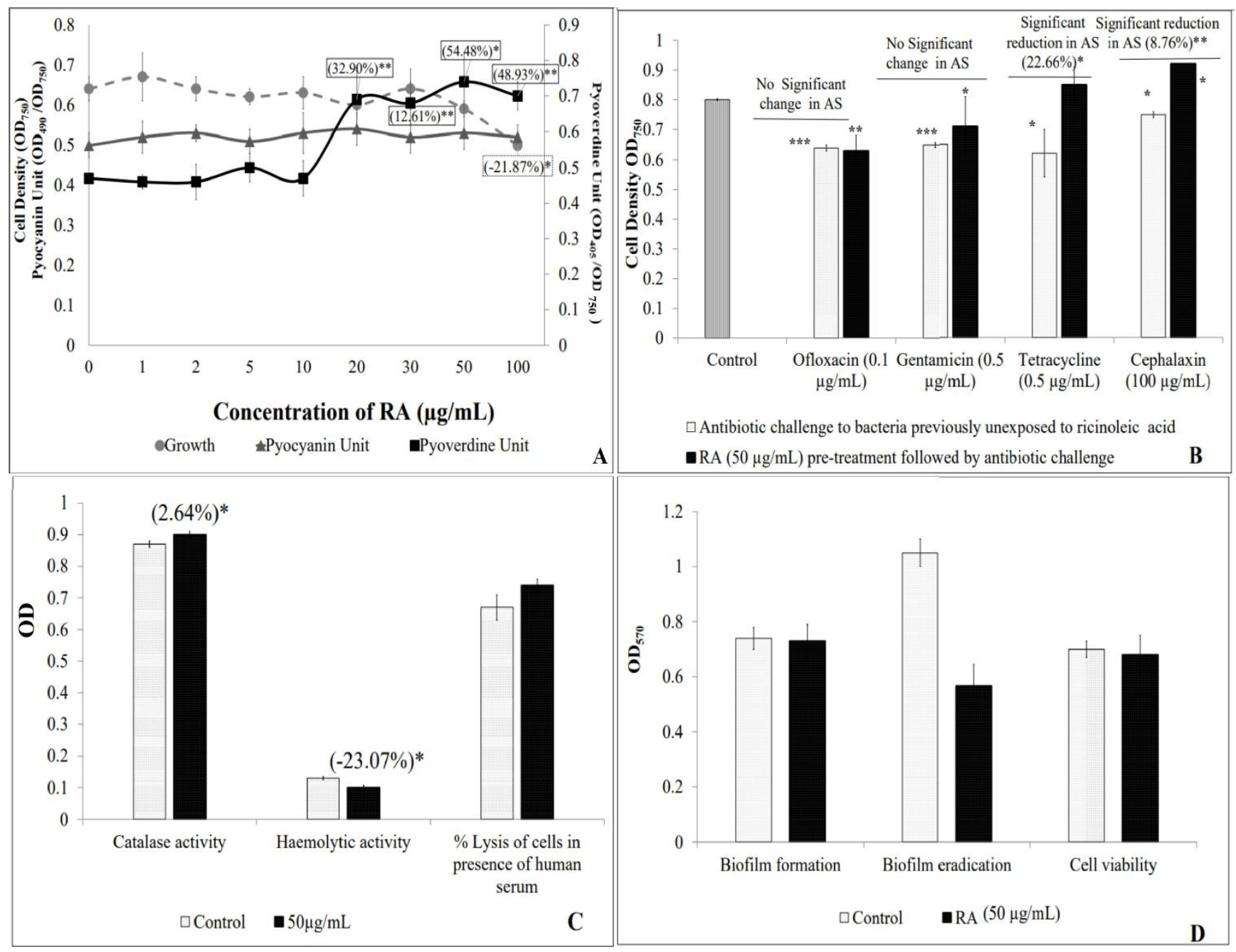

Figure 11. Effect of ricinoleic acid on Pseudomonas aeruginosa

${ }^{*} p<0.05$, **p<0.01, ***p<0.001; AS: Antibiotic susceptibility; QS: Quorum sensing; RA: Ricinoleic acid; PBS: Phosphate buffer saline (A) Effect of RA on growth and QS-regulated pigment production in P. aeruginosa: Bacterial cell density was quantified as $\mathrm{OD}_{750}$; OD of pyoverdine was measured at $405 \mathrm{~nm}$, Pyocyanin was measured at $490 \mathrm{~nm}$. Pyoverdine Unit was calculated as the ratio $\mathrm{OD}_{405} / \mathrm{OD}_{750}($ an indication of pyoverdine production per unit of growth); Pyocyanin Unit was calculated as the ratio $\mathrm{OD}_{490} / \mathrm{OD}_{750}$ (an indication of pyocyanin production per unit of growth). (B) RA-pre-treatment modulates susceptibility of $\boldsymbol{P}$. aeruginosa to different antibiotics.

(C) RA enhances catalase activity and inhibits haemolytic activity, but had no effect on susceptibility of $P$.

aeruginosa to lysis by human serum: Catalase activity was assessed by monitoring disappearance of $\mathrm{H}_{2} \mathrm{O}_{2}$ at $240 \mathrm{~nm}$; Hemoglobin concentration was measured as $\mathrm{OD}_{490} .1 \%$ triton served as the positive control $\left(\mathrm{OD}_{490}=1.5\right)$, and PBS served as the negative control $\left(\mathrm{OD}_{490}=0.01\right)$ for this assay; 'Control' in serum-dependent lysis assay was RA-unexposed cells of $P$. aeruginosa incubated with human serum. (D) RA had no effect on $P$. aeruginosa biofilm formation, eradication, and biofilm viability: Crystal violet assay was performed to measure biofilm formation, and biofilm eradication, followed by the measurement of OD at $570 \mathrm{~nm}$; Cell viability in biofilm was estimated through MTT assay, wherein OD was measured at $570 \mathrm{~nm}$. 


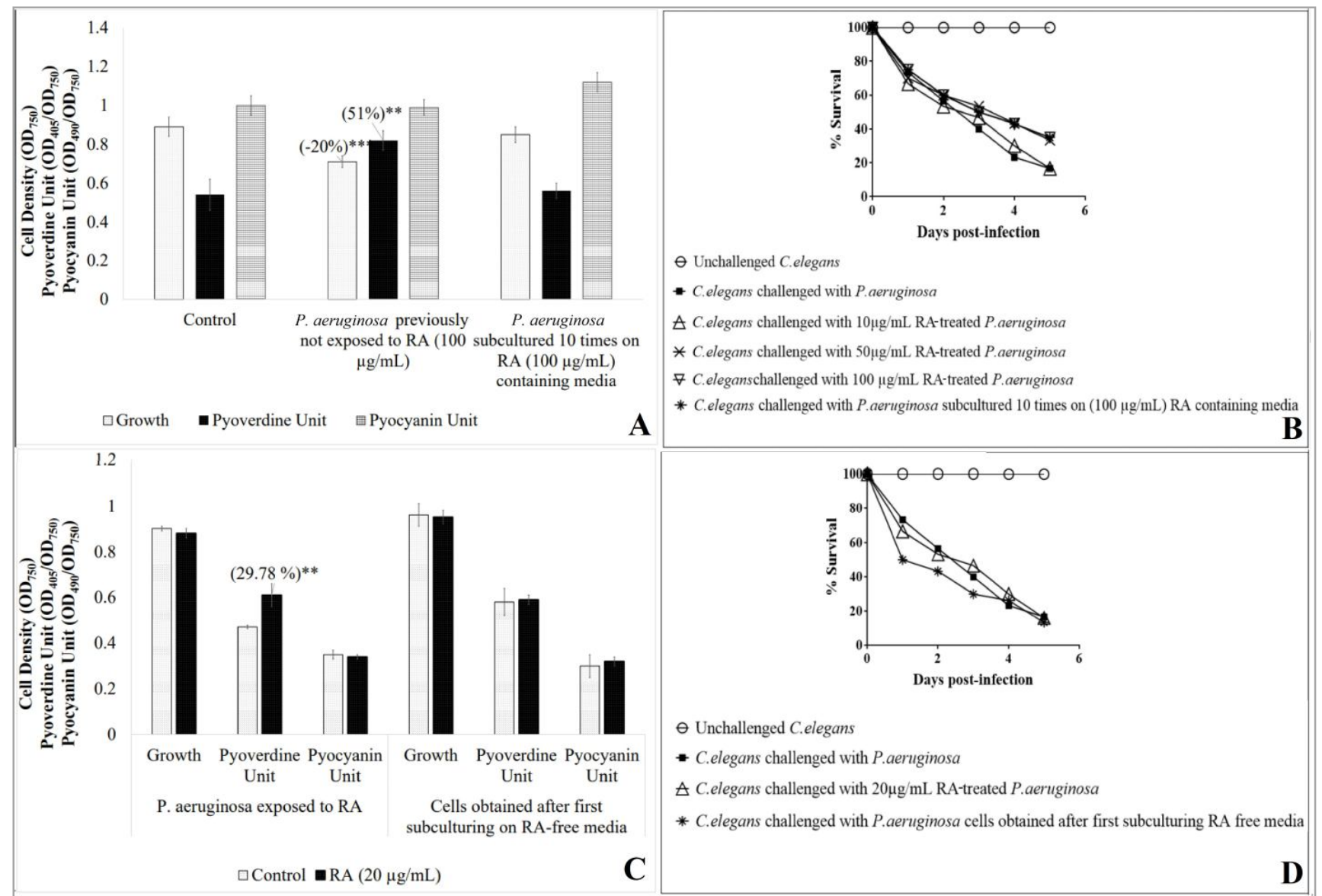

Figure 12. Effect of ricinoleic acid on various traits of $P$. aeruginosa, in vitro and in vivo ${ }^{*} p<0.05, * * p<0.01, * * * p<0.001 ;$ RA: Ricinoleic acid

(A) Effect of RA on P. aeruginosa growth and pigment productions altered after repeated exposure to RA: Bacterial cell density was quantified as $\mathrm{OD}_{750}$; OD of pyoverdine was measured at $405 \mathrm{~nm}$, Pyocyanin was measured at $490 \mathrm{~nm}$. Pyoverdine Unit was calculated as the ratio $\mathrm{OD}_{405} / \mathrm{OD}_{750}$ (an indication of pyoverdine production per unit of growth); Pyocyanin Unit was calculated as the ratio $\mathrm{OD}_{490} / \mathrm{OD}_{750}$ (an indication of pyocyanin production per unit of growth) (B) RA-treatment reduces the virulence of $\boldsymbol{S}$. marcescens towards C. elegans: Catechin $(50 \mu \mathrm{g} / \mathrm{mL})$ and gentamicin $(0.1 \mu \mathrm{g} / \mathrm{mL})$ employed as positive controls conferred $100 \%$ protection on worm population RA at $10 \mu \mathrm{g} / \mathrm{mL}, 50 \mu \mathrm{g} / \mathrm{mL}, 100 \mu \mathrm{g} / \mathrm{mL}$, and repeated exposure 10 times on $\mathrm{RA}(100 \mu \mathrm{g} / \mathrm{mL})$ containing media is $0 \%, 16.67 \% * * \pm 2.35$, $23.34 \% * * * \pm 1.18$ survival benefit respectively. Survival benefit refers to the difference between number of worms surviving in experimental and control wells. DMSO present in the 'vehicle control' at $0.5 \% \mathrm{v} / \mathrm{v}$ did not affect virulence of the bacterium towards C. elegans; DMSO $(0.5 \% \mathrm{v} / \mathrm{v})$ and

RA at tested concentrations showed no toxicity towards $C$. elegans. (C) No Post Extract Effect of RA on P. aeruginosa was observed in vitro (D) Post-extract effect of RA on $P$. aeruginosa in vivo 


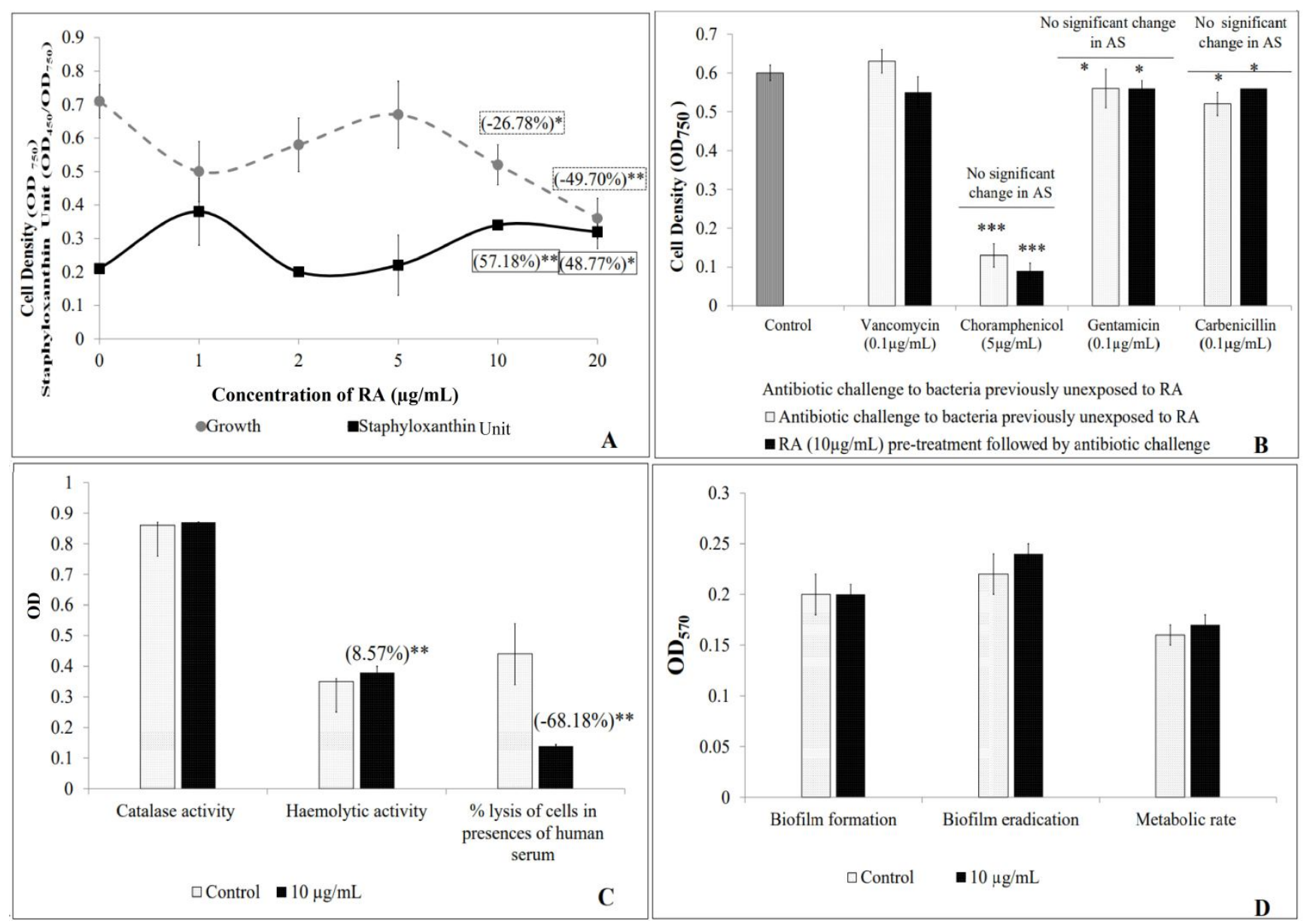

Figure 13. Effect of ricinoleic acid on Staphylococcus aureus

${ }^{*} p<0.05$, ${ }^{*} p<0.01,{ }^{* * *} p<0.001$; AS: Antibiotic susceptibility; QS: Quorum sensing; RA: Ricinoleic acid, PBS: Phosphate buffer saline

(A) Effect of RA on growth and QS-regulated pigment production in S. aureus: Bacterial cell density was quantified as

$\mathrm{OD}_{750}$; OD of staphyloxanthin was measured at $450 \mathrm{~nm}$, and Staphyloxanthin Unit was calculated as the ratio $\mathrm{OD}_{450} / \mathrm{OD}_{750}$ (an indication of

staphyloxanthin production per unit of growth). (B) RA pre-treatment modulates susceptibility of S. aureus to different antibiotics. (C) RA had no effect on catalase activity, enhances haemolytic activity, and modulates susceptibility of

S. aureus to lysis by human serum: Catalase activity was assessed by monitoring disappearance of $\mathrm{H}_{2} \mathrm{O}_{2}$ at $240 \mathrm{~nm}$. Hemoglobin concentration was measured as $\mathrm{OD}_{490} .1 \%$ triton served as the positive control $\left(\mathrm{OD}_{490}=1.5\right)$, and PBS served as the negative control $\left(\mathrm{OD}_{490}=0.03\right)$ for this assay. 'Control' in serum-dependent lysis assay was RA-unexposed cells of $S$. aureus incubated with human serum. (D) RA could not affect

the biofilm formation, eradication, and biofilm viability: Crystal violet assay was performed to measure biofilm formation, and biofilm eradication, followed by the measurement of OD at $570 \mathrm{~nm}$; Cell viability in biofilm was estimated through MTT assay, wherein OD was measured at $570 \mathrm{~nm}$. 


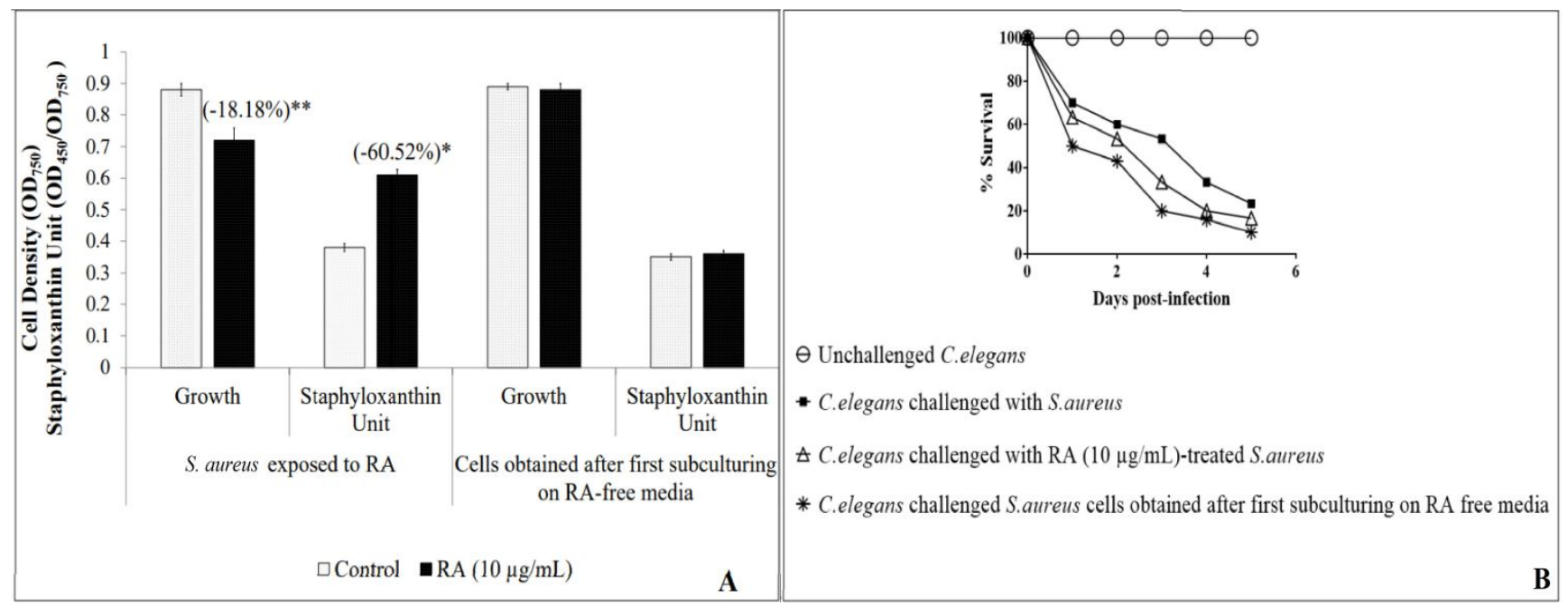

Figure 14. No Post Extract Effect of ricinoleic acid on $S$. aureus was observed (A) in vitro (B) in vivo $p<0.05$, ** $p<0.01$; RA: Ricinoleic acid

Bacterial cell density was quantified as $\mathrm{OD}_{750}$; $\mathrm{OD}$ of staphyloxanthin was measured at $450 \mathrm{~nm}$, and Staphyloxanthin Unit was calculated as the ratio $\mathrm{OD}_{450} / \mathrm{OD}_{750}$ (an indication of staphyloxanthin production per unit of growth).

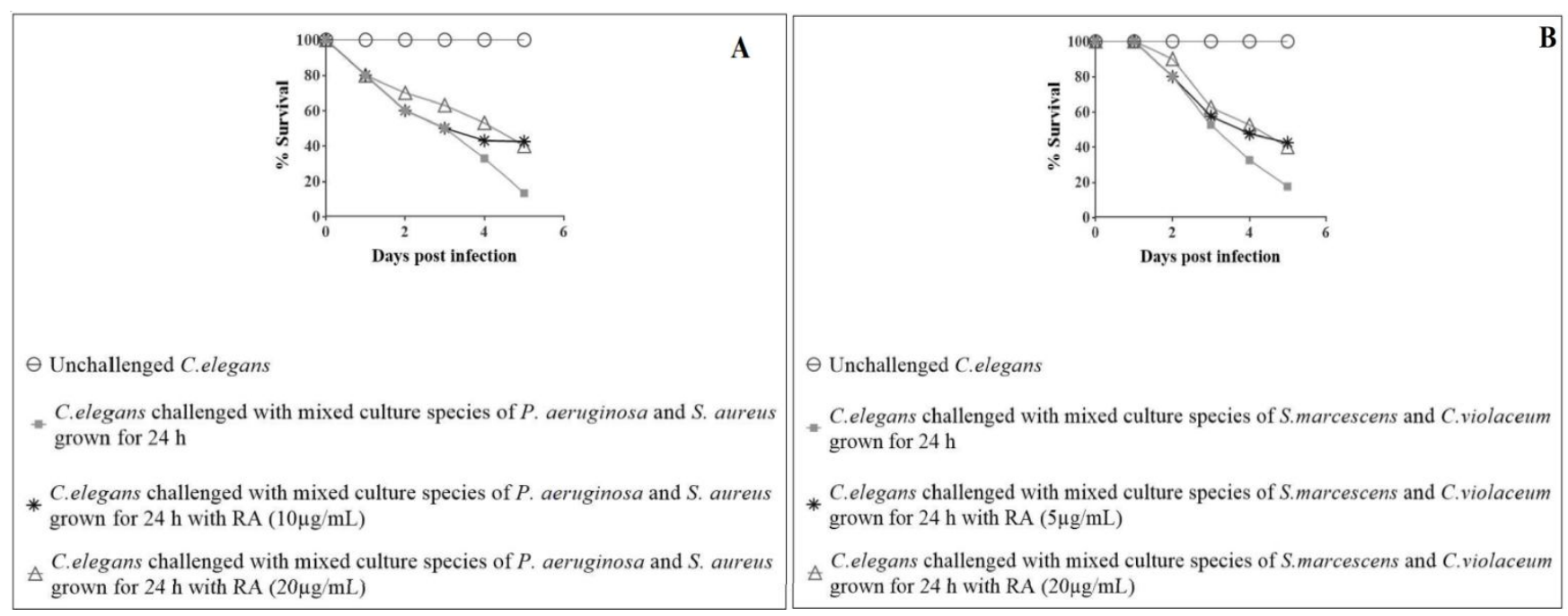

Figure 15. Effect of RA on mix-species culture of test pathogens

RA: Ricinoleic acid

(A) Anti-virulence effect of RA on mix-species culture of P. aeruginosa and S. aureus (B) Anti-virulence effect of RA

(B) on mix-species culture of $S$. marcescens and $C$. violaceum 


\section{Acknowledgement}

Authors thank Nirma Education and Research Foundation (NERF) for infrastructural and financial support.

\section{References}

Biswas et al. Investigation on possible anti-infective potential of castor oil and ricinoleic acid against selected bacterial pathogens. 2018, Dissertation Thesis, Nirma University.

Joshi C, Patel P, Kothari V. Anti-infective potential of hydroalcoholic extract of Punica granatum peel against gram-negative bacterial pathogens. F1000Research. 2019; 8. https://doi.org/10.12688/f1000research.17430.2

Patel P, Joshi C, Kothari V. Anti-pathogenic potential of a polyherbal wound-care formulation (herboheal) against certain wound-infective gram-negative bacteria. Advances in Pharmacological Sciences. 2019; 2019. https://doi.org/10.1155/2019/1739868

Patel VR, Dumancas GG, Viswanath LC, Maples R, Subong BJ. Castor oil: properties, uses, and optimization of processing parameters in commercial production. Lipid Insights. 2016;9: 1-12. 